\title{
Age and marital status are major factors associated with institutionalisation in elderly Hong Kong Chinese
}

\author{
J Woo, S C Ho, J Lau, Y K Yuen
}

\begin{abstract}
Study objective - To determine the need for long term institutional care for elderly Chinese living in Hong Kong and factors associated with institutional living.

Design - Survey by interviewer administered questionnaire of a stratified random sample of all recipients of old age or disability allowance covering $90 \%$ of the population.
\end{abstract}

Setting - Survey performed in Hong Kong, a city on the south coast of China with an area of $1070 \mathrm{~km}^{2}$ and approximately six million people.

Participants - A total of 2032 subjects aged 70 years and over (999 men, 1033 women) participated.

Main Results - Overall, $16 \%$ of the elderly live in institutions. The percentage is higher in women and in the older age group (81\% for those aged 80 years and over). After adjusting for age and sex, the following factors were positively associated with institutionalisation: poor cognitive function, measures of functional disability, poor vision, Parkinson's disease, stroke, and past fractures. Multivariate analysis identified age and marital status as associated factors with the highest odds ratio $(13.6$ and $7 \cdot 1$ respectively), followed by various disability indicators.

Conclusion - The survey shows that requirements for long term care places are unlikely to be much affected by preventive measures, and would need to increase by about $30 \%$ by 2000 to cope with the projected increase in the number of elderly aged 70 years and over. Measures to provide sufficient trained personnel and policy for regulation of standards should be made.

\section{( $\mathcal{F}$ Epidemiol Community Health 1994;48:306-309)}

The elderly Chinese population in Hong Kong aged 70 years and over forms approximately $7 \%$ of the total population, and is projected to increase by $33 \%$ by the year $2000 .^{1}$ Provision of long term institutional places is an important component of geriatric services. Requirement for these services depends on the number of elderly people, social and cultural factors, the prevalence of chronic disabling diseases (mental and physical), and the development of community resources. ${ }^{2}$ Although some factors predisposing to institutionalisation may be modifiable, such as improvement in community support, it is recognised that a proportion of people will always need institutional care. ${ }^{3}$ In our population, there is no information about the percentage of the elderly population using this service or factors associated with institutional care. Such information is required for future planning of service provision and for identification of modifiable factors that may reduce the need for institutional care. The aims of this study are to establish the prevalence of institutionalisation in elderly Chinese aged 70 years and over and to examine factors associated with institutional care.

\section{Methods}

A survey was carried out on a group of elderly Chinese aged 70 years and over selected by stratified random sampling from a registered list of all recipients of old age and disability allowances. The old age allowance list covers over $90 \%$ of the elderly aged 70 years and over, since eligibility is by age alone, independent of income. The remaining $10 \%$ of the elderly would be the very rich who may not elect to claim the allowance. The disability allowance list covers those subjects who may be receiving additional social welfare support. Subjects were stratified by age and sex so that there were 300 subjects in the 70-74 and 75-79 age groups in each sex, and 150 subjects in the 80$84,85-89,90+$ age groups in each sex. Enough letters were sent to these subjects to recruit the required numbers in each cell. Approximately $60 \%$ of men and women agreed to the interview. The response rate was higher in the older men aged 80 years and above $(66 \%)$ and slightly lower in women aged $70-79(53 \%)$. The numbers interviewed consisted of 999 men and 1033 women.

Interviewers visited those subjects who agreed to the interview and a questionnaire was administered. This consisted of information on social, functional, physical, and mental health status, and place of residence. Functional status was assessed by the Barthel Index, ${ }^{4}$ mental function by the information/ orientation part of the Clifton Assessment Procedure for the Elderly, ${ }^{5}$ and depressive symptoms by the Geriatric Depression Scale. ${ }^{6}$ Subjects also performed a walking test, where the time and the number of steps taken to walk along a straight line of 16 feet were measured. The place of residence was classified as "institution" by the interviewer, when it fell into one of the following categories: old age hostel, 
old age home, care and attention home, or private nursing home. The first three categories are old age homes run by government funding and catering for elderly people with varying degrees of disability.

Results were analysed using an IBM mainframe computer and the Statistical Analysis System, 6.07 (SAS Institute Inc, Cary, NC). Factors associated with institutionalisation were determined using logistic regression.

\section{Results}

Overall, $16 \%$ of the elderly respondents aged 70 years and over lived in institutions (table 1 ). The percentage of elderly living in institutions rose with age, and there were approximately twice as many women in the oldest age groups living in institutions. The odds ratios for factors associated with institutionalisation after adjusting for age and sex are shown in table 2 . Only significant factors with a $p$ value $<0.01$ are shown. Factors with the highest odds ratio were marital status, income, dementia, and disability indicators. The four chronic diseases associated with institutional care were dementia, Parkinson's disease, stroke, and past fractures. Poor vision was also a significant factor, although the $p$ value is only $<0.05$ and may not represent a valid association since a large number of associations had been explored. Subjects in institutions tend to use slightly more prescription drugs $(\mathrm{p}<0.05)$ and attended clinics more frequently. However, there were fewer subjects taking any types of drug (including non-prescription drugs), fewer subjects complaining that joint pain restricted activities, and less smoking ( $p$ only $<0.05$ ) and alcohol consumption in institutions. More subjects in institutions failed to

Table 1 Place of residence by age and sex

\begin{tabular}{|c|c|c|c|}
\hline & $\begin{array}{l}\text { Community } \\
\text { No }(\%)\end{array}$ & $\begin{array}{l}\text { Institution } \\
\text { No }(\%)\end{array}$ & $\begin{array}{l}\text { Total } \\
\text { No }(100 \%)\end{array}$ \\
\hline $\begin{array}{l}\text { Male*t: } \\
70-74 \\
75-79 \\
80-84 \\
85-89 \\
90+\end{array}$ & $\begin{array}{r}290(99 \cdot 0) \\
279(92 \cdot 1) \\
122(81 \cdot 3) \\
102(71 \cdot 3) \\
72(65 \cdot 5)\end{array}$ & $\begin{array}{c}3(1.0) \\
24(7.9) \\
28(18.7) \\
41(28.7) \\
38(34.5)\end{array}$ & $\begin{array}{l}293 \\
303 \\
150 \\
143 \\
110\end{array}$ \\
\hline Total & $865(86 \cdot 6)$ & $134(13 \cdot 4)$ & $999(100 \%)$ \\
\hline $\begin{array}{l}\text { Adjusted prevalence } \\
(\% \text {; and } 95 \% \mathrm{CI})\end{array}$ & $92 \cdot 9 ; 89 \cdot 6,96 \cdot 3$ & $7 \cdot 1 ; 6 \cdot 3,7 \cdot 8$ & \\
\hline $\begin{array}{c}\text { Female*: } \\
70-74 \\
75-79 \\
80-84 \\
85-89 \\
90+\end{array}$ & $\begin{array}{r}278(95.5) \\
239(83.9) \\
85(53.8) \\
64(44.8) \\
59(37.8)\end{array}$ & $\begin{array}{l}13(4 \cdot 5) \\
46(16 \cdot 1) \\
73(46 \cdot 2) \\
79(55 \cdot 2) \\
97(62 \cdot 2)\end{array}$ & $\begin{array}{l}291 \\
285 \\
158 \\
143 \\
156\end{array}$ \\
\hline Total & $725(70 \cdot 2)$ & $308(29 \cdot 8)$ & $1033(100 \%)$ \\
\hline $\begin{array}{l}\text { Adjusted prevalence } \\
(\% ; \text { and } 95 \% \mathrm{CI})\end{array}$ & $78 \cdot 4 ; 75 \cdot 5,81 \cdot 3$ & $21 \cdot 6 ; 20 \cdot 4,22 \cdot 8$ & \\
\hline $\begin{array}{l}\text { Male and female*: } \\
70-74 \\
75-79 \\
80-84 \\
85-89 \\
90+\end{array}$ & $\begin{array}{l}568(97 \cdot 3) \\
518(88 \cdot 1) \\
207(67 \cdot 2) \\
166(58 \cdot 0) \\
131(49 \cdot 2)\end{array}$ & $\begin{array}{c}16(2 \cdot 7) \\
70(11 \cdot 9) \\
101(32 \cdot 8) \\
120(42 \cdot 0) \\
135(50 \cdot 8)\end{array}$ & $\begin{array}{l}584 \\
588 \\
308 \\
286 \\
266\end{array}$ \\
\hline Total & $1590(78 \cdot 2)$ & $442(21 \cdot 8)$ & $2032(100 \%)$ \\
\hline $\begin{array}{l}\text { Adjusted prevalence } \\
(\% \text {; and } 95 \% \mathrm{CI})\end{array}$ & $84 \cdot 4 ; 81 \cdot 6,87 \cdot 1$ & $15 \cdot 6 ; 14 \cdot 5,16 \cdot 7$ & \\
\hline
\end{tabular}

* Significantly different between age groups by $\chi^{2}, p<0.001$

+ Significantly different between sexes by $\chi^{2}, \mathrm{p}<0.001$. perform the 16 feet walk, required walking aids, and took more time and more steps to complete the walk, although the $p$ value for the last two variables was only $<0.05$. Among the components of the Barthel Index, walking, toiletting, and bathing problems had the highest odds ratios. Education, presence of other chronic diseases such as cardiorespiratory diseases, hypertension, diabetes mellitus, and high depression score were not significant associated factors.

In multivariate analysis of variables showing significant association in univariate analysis, age and marital status showed the highest odds ratios, followed by disability indicators (table 3). However, the odds ratios for the latter were much lower. Other significant factors remaining in the model were poor mental score, prescription drug use, and clinic visits. Joint pain that restricted activities had a negative association with institutionalisation.

\section{Discussion}

The pool of elderly subjects from which the survey sample was drawn may be considered representative of elderly people aged 70 years and over in Hong Kong, since it covers over $90 \%$ of this age group. Although the response rate was only $60 \%$, response rates in surveys of the elderly, particularly the old elderly, are not usually very high. Thus, in a survey of community-living elderly aged 65 years and over in the UK, the response rate was approximately $60 \% .^{7}$ We were unable to obtain information on non-responders, as laws of confidentiality prohibited us from contacting these subjects if no written consent was obtained. Therefore it is possible that there may be higher numbers of subjects living in institutions among nonresponders, so that the prevalence of institutionalisation may have been underestimated.

The prevalence of subjects requiring institutionalisation may be compared with other countries. However, the comparison is only approximate, since the figure is not adjusted to a standardised population. Compared with studies in the UK, a higher percentage of elderly (particularly women) live in institutions. Twenty one per cent of women and $7 \%$ of men aged 70 years and over lived in institutions and this rose with age, similar to figures for the UK (6-21\% for women and $4-13 \%$ for men), ${ }^{8}$ and USA $(20 \%){ }^{2}$

The percentage of elderly people living in institutions rises fourfold from the 70-79 age group to the $80+$ age group, with a female to male predominance in the latter. After adjusting for age and sex, marital status and financial reliance on social welfare, and various factors indicative of disability, were strongly associated with institutionalisation. Odds ratios of less than one for smoking and alcohol intake may be explained by institution regulations prohibiting these activities. As subjects may have low mobility, they would be less likely to complain that joint pain restricted activities. They also used less non-prescription drugs, so that overall drug use was less inspite of higher use of prescription drugs. This is not surpris- 
Table 2 Odds ratio for factors associated with institutionalisation, adjusted for age and sex

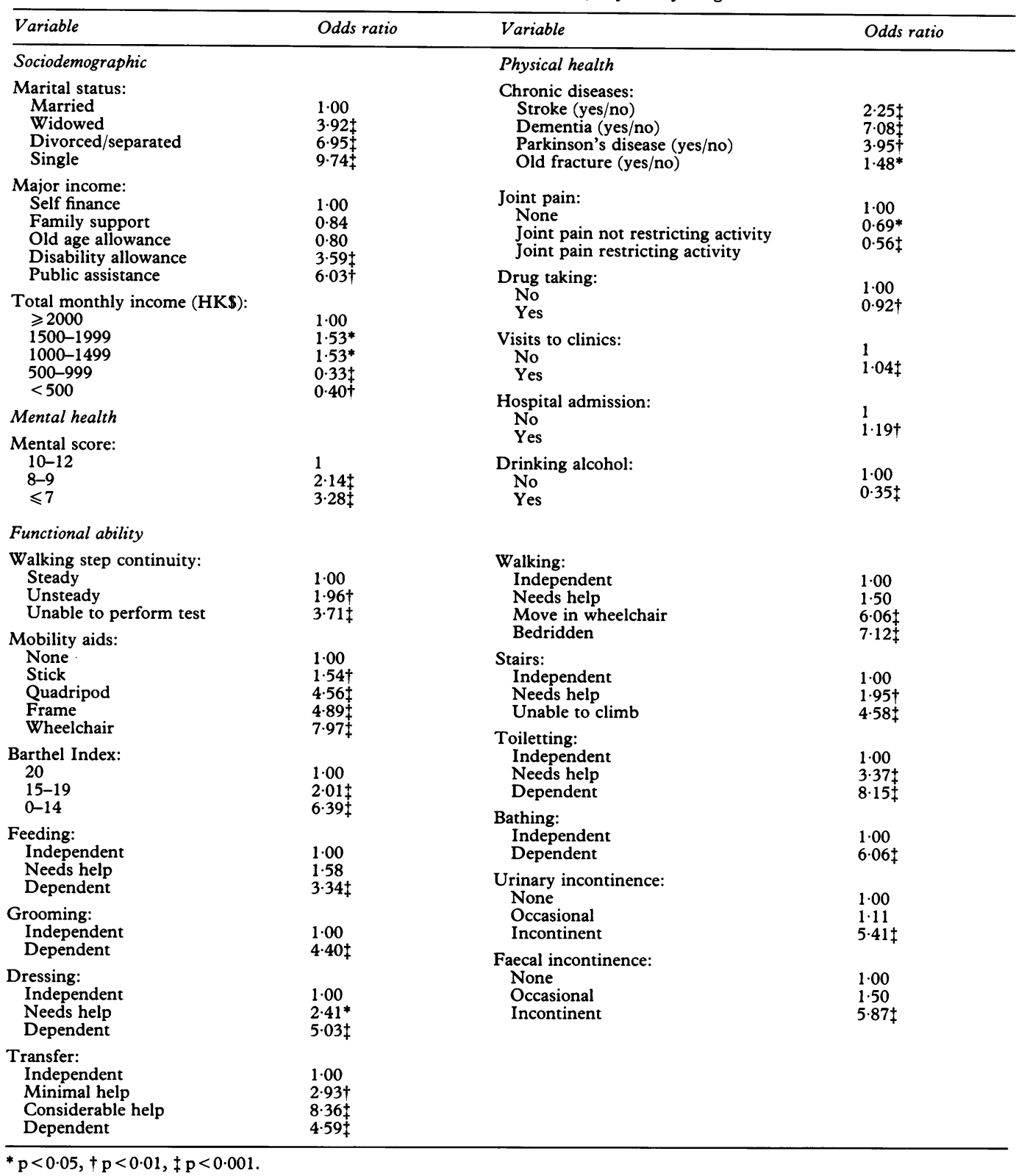

ing since residents in most institutions will not be able to go to pharmacies to buy over the counter drugs, while they would be accompanied to see the doctor. The time and number of steps taken to perform the 16 feet walk is an indication of gait and muscle strength. The former shows age associated changes with longer time taken and smaller steps, possibly indicating a tendency towards Parkinsonism. ${ }^{9}$ Muscle strength has been shown to be one of the factors in contributing to walking speed in men. ${ }^{10}$ However, when all factors were included in a multivariate logistic model, the highest odds ratios were age and marital status only (14 and 7), with disability indicators having odds ratios of less than 3 . In a prospective study in the USA, factors predisposing to nursing home entry included age, race, number of instrumental activities of daily living limitations, caregiver burden, and use of formal services. ${ }^{11}$ Similarly a Japanese study showed that the female sex, low activities of daily living, and living alone were factors predisposing to long term institutional care after adjusting for disability. ${ }^{12}$ A follow up study would be able to confirm these findings.

Estimates regarding future provision of places in institutions can be made from this study and the projected increase in the population aged 70 years and above. If $16 \%$ of the elderly aged 70 years and above live in institutions (table 1), and the total population of this age group is 304545 , the absolute number of elderly aged 70 years and above living in institutions is approximately 48727 . Assuming that there will be no change in the percentage living in institutions due to possible changes in predisposing factors in future years, the number will rise to 64807 by the year 2000 - that is by $33 \%$ - given the predicted rise in the numbers of this age group among the whole population from figures supplied by the Government Census and Statistics Department. At present, roughly one sixth of institu- 
Table 3 Multiple logistic regression of significant variables associated with institutionalisation

\begin{tabular}{|c|c|c|}
\hline Variable & Odds ratio & - $95 \%$ Confidence interval \\
\hline $\begin{array}{l}\text { Age: } \\
70-74 \\
75-79 \\
80-84 \\
85-89 \\
90+\end{array}$ & $\begin{aligned} 1.00 \\
3.90 \ddagger \\
9 \cdot 79 \ddagger \\
11.97 \ddagger \\
13 \cdot 62 \ddagger\end{aligned}$ & $\begin{array}{l}1 \cdot 98,7 \cdot 70 \\
4 \cdot 89,19 \cdot 58 \\
5 \cdot 94,24 \cdot 12 \\
6 \cdot 61,28 \cdot 06\end{array}$ \\
\hline $\begin{array}{l}\text { Marital status: } \\
\text { Married } \\
\text { Widowed } \\
\text { Divorced/separated } \\
\text { Single }\end{array}$ & $\begin{array}{l}1 \cdot 00 \\
4 \cdot 21 \ddagger \\
4 \cdot 90 \dagger \\
7 \cdot 08 \ddagger\end{array}$ & $\begin{array}{l}2 \cdot 79,6 \cdot 34 \\
1 \cdot 58,15 \cdot 21 \\
3 \cdot 87,12 \cdot 96\end{array}$ \\
\hline $\begin{array}{l}\text { Major income: } \\
\text { Self-finance or family support } \\
\text { Old age allowance } \\
\text { Public assistance } \\
\text { Disability allowance }\end{array}$ & $\begin{array}{l}1 \cdot 00 \\
2 \cdot 17^{*} \\
5 \cdot 30_{\ddagger}^{+} \\
2 \cdot 06^{*}\end{array}$ & $\begin{array}{l}1 \cdot 13,4 \cdot 16 \\
3 \cdot 55,7 \cdot 93 \\
1 \cdot 15,3 \cdot 68\end{array}$ \\
\hline $\begin{array}{l}\text { Total income (HK\$): } \\
>=2000 \\
1500-1999 \\
1000-1499 \\
500-999 \\
<500\end{array}$ & $\begin{array}{l}1.00 \\
1.30 \\
0.93 \\
0.30 \ddagger \\
0.33^{*}\end{array}$ & $\begin{array}{l}0 \cdot 77,2 \cdot 17 \\
0 \cdot 58,1 \cdot 51 \\
0 \cdot 16,0 \cdot 56 \\
0 \cdot 14,0 \cdot 79\end{array}$ \\
\hline $\begin{array}{l}\text { Mental score: } \\
\text { Good }(10-12) \\
\text { Fair }(8-9) \\
\text { Poor }(<=7)\end{array}$ & $\begin{array}{l}1 \cdot 00 \\
1 \cdot 81 \dagger \\
1 \cdot 85 \dagger\end{array}$ & $\begin{array}{l}1 \cdot 24,2 \cdot 63 \\
1 \cdot 26,2 \cdot 72\end{array}$ \\
\hline $\begin{array}{l}\text { Bathing: } \\
\text { Independent } \\
\text { Dependent/needs help }\end{array}$ & $\begin{array}{l}1 \cdot 00 \\
2 \cdot 63 \ddagger\end{array}$ & $1.51,4.59$ \\
\hline $\begin{array}{l}\text { Joint pain: } \\
\text { None or joint pain not restricting activity } \\
\text { Restricts activity }\end{array}$ & $\begin{array}{l}1.00 \\
0.58 \ddagger\end{array}$ & $0.41,0.82$ \\
\hline $\begin{array}{l}\text { Drug Taking: } \\
\text { Yes/No }\end{array}$ & $0 \cdot 81_{+}^{+}$ & $0.74,0.89$ \\
\hline $\begin{array}{l}\text { Prescription drugs taking: } \\
\text { Yes/No }\end{array}$ & $2 \cdot 17_{\ddagger}^{+}$ & $1 \cdot 43,3.29$ \\
\hline $\begin{array}{l}\text { Visit to outpatient's dept or clinic: } \\
\text { Yes/No }\end{array}$ & $1 \cdot 04 \ddagger$ & $1.02,1.06$ \\
\hline
\end{tabular}

${ }^{*} \mathrm{p}<0.05,+\mathrm{p}<0.01, \mp \mathrm{p}<0.001$. mand for institutional care is increasing or improving community support. However, it cannot be assumed that community care is preferable to institutional care, since there is no information about the preference of the elderly or comparative costs in this community. Indeed, community care may be more expensive and may result in abuse of the elderly. ${ }^{8}$ Standards of care in institutions may be improved with quality assurance programmes. With acceptance of a dependent role, some elderly subjects may prefer institutional care. ${ }^{2}$ Thus a proportion will always need institutional care despite the development of community care. ${ }^{2}$ However, improving the effectiveness of community care may influence the preference of elderly subjects for home versus institutional care.

In conclusion, this study shows that age and social circumstances are the main factors associated with institutionalisation, followed by functional disability, so that the requirement for institutional places may not be reduced to a great extent by any preventive measures. The implications for health and social service provisions are that places should be increased by about $30 \%$ by 2000 to cope with increased demands. Adequate funds should be set aside, and plans to recruit and train enough numbers of health care personnel should be made. Policy for regulation of standards should also be developed.

1 Census and Statistics Department. Annual report. Hong Kong: Hong Kong Government.

2 Hirschfield MJ, Fleishman R. Nursing home care for the elderly. In: Kane RL, Evans JG, MacFadyen D. eds. Improving the health of older people. Oxford: Oxford Improving the health

tions are funded by the government, the rest are privately run. It is likely that the number of private homes will increase much faster to cope with increasing demands, as in the UK. ${ }^{13}$ Standards of care may fall, as they are difficult to regulate and there may not be a parallel increase in trained personnel. The total number of institution places should be increased to cope with this anticipated demand.

The number of elderly requiring institutional care may theoretically be reduced by modifying associated risk factors. Although primary preventive measures may reduce the burden of chronic disease and hence functional disability, this factor does not seem to be a major one when compared with age and marital status, which are not modifiable. Therefore efforts aimed at prevention are not likely to affect demands for institutional care significantly. Nevertheless, measures to reduce the burden of chronic disease or to reduce functional disability would still be important targets in prevention.

Another factor which may reduce the de-

Challis C, Davies B. The community care approach: an innovation in home care by social service departments. In Wells N, Freer C, eds. The ageing population: burden or challenge? London: MacMillan, 1988.

4 Mahoney FI, Barthel DW. Functional evaluation: the Barthel Index: reliability study. Maryland State Medical fournal 1965;14:61-5.

5 Pattie AH, Gilleard CJ. The Clifton Assessment Schedule: further validation of a psychogeriatric assessment schedule. Br F Psychiatry 1976;129:68-72.

6 Yesavage JA, Brink TL. Development and validation of a geriatric depression screening scale: A preliminary report. f Psychiatr Res 1983;17:37-49.

7 Dewhurst G, Wood DA, Walker F, Lampe FC, Jeffreys $M$ Cooper $M$, Williams JD. A population survey of cardiobascular disease in elderly people: design, methods, and prevalence results. Age Ageing 1991;20:353-60.

prevalence results. Age Ageing 1991;20:353-60.
8 Victor CR. Health and health care in later life. Buckingham: Open University Press, 1991.

9 Dobbs RJ, Lubel DD, Charlett A, Bowes SG, O'Neill CJA, Weller C, Dobbs SM. Hypothesis: age-associated changes in gait represent, in part, a tendency towards Parkinsonism. Age Ageing 1992;21:221-5.

10 Bendall MJ, Bassey EJ, Pearson MB. Factors affecting walking speed of elderly people. Age Aging 1989;18:32732.

11 McFall S, Miller BH. Caregiver burden and nursing home admission of frail elderly perons. $f$ Gerontol 1992;47:S73S79.

12 Kuroda K, Tatara K, Takatorige T, Zhao L, Shinsho F. Factors related to longterm stay in hospital by elderly people in a Japanese city. Age Ageing 1992;21:321-7.

13 Stern MC, Jagger C, Clarke M, Anderson J, McGrother C Battock T, MacDonald C. Residential care for elderly people - a decade of change. BMF 1993;306:827-30. 